\title{
Diet, delusion and diabetes
}

\author{
L. Sawyer • E. A. M. Gale
}

Published online: 19 November 2008

(C) Springer-Verlag 2008

Progress, far from consisting in change, depends on retentiveness. [...] When experience is not retained, as among savages, infancy is perpetual. Those who cannot remember the past are condemned to repeat it.

George Santayana (1905) [1]

The history of diabetes is marked by recurrence of certain ideas which rise, decline and disappear; only to go through a similar cycle again in an altered form and a new generation.

R. T. Woodyatt (1934) [2]

\section{Futile cycles?}

Diet is good for diabetes, as everyone agrees, but which diet? The word itself has acquired such negative associations that professionals now prefer to talk of medical nutrition therapy, abbreviated to MNT to avoid the negative connotations of the word 'nutrition'. Shakespeare said that 'a rose by any other name would smell as sweet', but it will still have thorns, and we will continue to call a diet a diet. Three related

L. Sawyer

Department of Dietetics, North Bristol Trust, Southmead Hospital, Bristol, UK

\section{E. A. M. Gale ( $\bowtie)$}

Diabetes and Metabolism, Medical School Unit,

Southmead Hospital,

Bristol BS10 5NB, UK

e-mail: Edwin.Gale@bristol.ac.uk health benefits might be expected from a diet for diabetes: improved metabolic control, weight loss, and reduced risk of vascular disease. From a patient's point of view, you diet because you want to lose weight, a desire typically expressed in the future conditional, as in 'I really must think about going on a diet'. Overweight cannot be divorced from emotion, and its consequences cannot be measured in kilograms, for its true costs to the individual must be paid in the currency of the soul. Let us therefore ask a much simpler question: weight loss apart, which diet is best for diabetes? The recent American Diabetes Association (ADA) guidelines, drafted in the light of 150 years of experience in the dietary management of diabetes, conclude that we lack the evidence needed to reach a conclusion [3]. Will we ever find the right answer? Or are we asking the wrong questions?

From an historical perspective, it is easy to see that the investigators of diet have confused circular motion with progress. The very low carbohydrate diets of the pre-insulin era yielded to the high carbohydrate diets of the late $1920 \mathrm{~s}$ and 1930s, and these gave way to the free diets of the 1930s through to the $1950 \mathrm{~s}$. The cycle then resumed with the low carbohydrate diet of the 1960 s, the high carbohydrate/high fibre diet of the 1970s, the free diets of the latter part of the century and the reincarnation of the pre-insulin regimen in the form of the Atkins diet. The enthusiasts have come and gone, each claiming unique virtue and spectacular success for their own particular regimen, and it would be hard to imagine a diet that has not at some stage constituted an article of faith in diabetes management. Almost all these diets worked some of the time, but we may suspect that few were followed with any degree of rigour for most of the time. 


\section{Early days}

It takes a brave physician to treat his own mother. Sarah Proctor Joslin developed the first symptoms of diabetes in the spring of 1899, and became Case No. 8 in Elliot Joslin's casebook (his aunt was Case No. 2). His mother's weight had fallen to $73 \mathrm{~kg}$ from its previous maximum of $84 \mathrm{~kg}$ (BMI $32 \mathrm{~kg} / \mathrm{m}^{2}$ ), and she was losing around $60 \mathrm{~g}$ of glucose per day in her urine. Joslin eliminated carbohydrate from her diet until the urine became sugar-free, and then replaced it in stages until glycosuria reappeared. She consumed some $40-75 \mathrm{~g}$ of carbohydrate daily for the remaining 14 years of her life, and obtained most of her remaining energy requirements from $150 \mathrm{~g}$ of fat. 'Eskimos live upon 52 grams of carbohydrate daily', Joslin noted, and this 'should greatly encourage diabetic patients' [4]. His mother's response has not been recorded.

Nineteenth century diets for diabetes were just as varied as those of the twentieth century. The Italian physician Cantani, who had a large and lucrative private practice, enforced starvation by locking his patients in their rooms and feeding them on lean meat, fat and dilute alcohol [5]. Most physicians agreed on the importance of calorie restriction in conjunction with intermittent fasts, and Joslin advised his patients to aim for a weight $10 \%$ below the population average for their age and sex. The actual composition of the diets on offer ranged from the diet followed by William Banting [6], which anticipated Atkins by more than a century, to high carbohydrate diets (offered in the context of overall calorie restriction) such as the milk cure, the von Düring vegetable cure, the Mossé potato cure and the oatmeal cure favoured by the Viennese physician Carl von Noorden [2].

Sandmeyer reported in 1895 that diabetes developed in two dogs 5 and 13 months following subtotal pancreatectomy [7], and Frederick Allen - one of the first to appreciate that diabetes involves total metabolism rather than carbohydrate metabolism alone-developed this model to show that complete removal of the organ resulted in uncontrolled diabetes and death, whereas dogs who retained more than $20 \%$ of their pancreas never developed diabetes. The fate of those with $80-90 \%$ pancreatectomy depended upon what they ate. 'On an Eskimo diet they may be found to live in health', said Allen, but 'on a Hindu diet they soon go down to fatal diabetes' [8]. Carbohydrate loading produced progressive glycosuria and hydropic degeneration of the islets, leading Allen to conclude that the as yet unknown pancreatic factor that prevented diabetes had been exhausted. Glucose toxicity had found its first advocate. Physiology also has its cycles, and investigators discovered in 1988 that glucose infusion precipitated pancreatic islet failure in dogs with subtotal pancreatectomy, little suspecting that they had reproduced one of the classic experiments in diabetes 75 years later [9].
Allen concluded that people with diabetes should be given just enough food to keep body and soul together, with as little carbohydrate as possible, and the starvation regimen was born [8]. The physician in charge of this diet has been described as a yachtsman sailing as close as possible to the wind [10]. Too many calories, and symptomatic hyperglycaemia would result; too few, and the patient would die of starvation (as some did). Naunyn had taught that 'fat burns in the fire of the carbohydrates', and carbohydrate was needed for the proper combustion of dietary fat, which might otherwise precipitate ketoacidosis. One risk having thus been balanced against another, a man weighing $60 \mathrm{~kg}$ and able to tolerate $100 \mathrm{~g}$ of carbohydrate might end up on $60 \mathrm{~g}$ of protein, $130 \mathrm{~g}$ of fat and $25 \mathrm{~g}$ of carbohydrate. His daily ration of the latter might consist of $7 \mathrm{oz}(198 \mathrm{~g})$ of thrice boiled cabbage, or $5 \mathrm{oz}(142 \mathrm{~g})$ of similarly treated spinach or two and a half bran biscuits [10]. The bran was needed to counteract the constipation induced by the rest of the diet.

Adults did relatively well on this regimen, but children hovered miserably between death from diabetes and death from starvation. One 12-year-old boy, already blind from diabetes, was reduced to eating toothpaste mixed with birdseed stolen from his pet canary. 'These facts were obtained by confession after long and plausible denials', remarked the pitiless Allen. The unfortunate child died of starvation. A few physicians hailed the treatment as a means of prolonging life, but Carl von Noorden shuddered and turned away when Joslin showed him one of his cases. The controversy concerning the value of extra months or years purchased at the cost of so much misery was very bitter, and Allen was banned from the diabetic clinic at the Rockefeller Institute in 1918 [11].

Terrible though they were, the pre-insulin diets prolonged life. Supplies of insulin were limited (and expensive) for some years after its discovery [12], and the starvation regimen kept many people alive until insulin went into full production. 'The unfortunate diabetic', as Sir Derrick Dunlop recalled, 'had to consume great quantities of green vegetables drenched in margarine. The palms of his hands were usually yellow because he could not convert into vitamin A all the carotene he took. He then had to balance large portions of butter on small squares of oatcake or buns made of soya-bean meal... but there is no doubt that many patients were well controlled on such diets and their insulin requirements were small' [10].

\section{High carbohydrate rediscovered}

Modern recalculation of the diets used by Joslin and Allen shows that, on average, $70 \%$ of calories were derived from fat, $10 \%$ from carbohydrate and $20 \%$ from protein [13]. To 
put this into context, almost everyone in the world outside the Arctic then ate a very high carbohydrate diet, and the 'Vogt standard', widely accepted by nutritionists, considered that a 3,000 calorie diet for a working man should include $500 \mathrm{~g}$ of carbohydrate ( $66 \%$ of calories), $56 \mathrm{~g}$ of fat and $118 \mathrm{~g}$ of protein [14]. Fat consumption increases with affluence, and the proportion of carbohydrate in the American diet fell by $25 \%$ over the next 50 years [15]. By the end of the century a highly diverse food culture was in place, and the third National Health and Nutrition Examination Survey (NHANES III) (1988-1994) found that the energy derived from dietary carbohydrate was $33.2 \%$ for the lowest and $64.3 \%$ for the highest quintile of US males, with a value of $48.5 \%$ for the middle quintile. Those in the lowest quintile were twice as likely to smoke as those in the highest $(43.9 \%$ vs $24.9 \%)$, whereas those in the highest quintile were twice as likely to abstain from alcohol $(43.8 \%$ vs 20.6\%); the same pattern was seen in women [16].

Physicians were slow to appreciate that insulin allowed the proportion of carbohydrate in the diet to be increased, for, as Himsworth said, 'a well-founded theory directs that the carbohydrates in the diabetic's diet must be curtailed if health is to be preserved'. On the other hand, as he continued, 'a brilliant piece of clinical empiricism produces irrefutable proof that a liberal allowance of carbohydrate acts favourably on the diabetic's health' [17]. This empiricism began in 1926, when a high carbohydrate diet was first shown to improve glucose tolerance in healthy individuals [18]. Noting this, William Sansum promptly increased the carbohydrate content of the diet of his Californian patients; a typical recommendation might include 2,435 calories, $245 \mathrm{~g}$ of carbohydrate ( $40 \%$ of energy requirements), $124 \mathrm{~g}$ of fat and $100 \mathrm{~g}$ of protein [19]. The benefit was dramatic, next only to insulin in the minds of its recipients, for it combined greatly increased well-being with escape from the miseries of an endless low carbohydrate diet. The carbohydrate component soon escalated, and a typical diet prescribed by the Canadian physician Israel Rabinowitch in the mid-1930s might contain 2,230 calories, $400 \mathrm{~g}$ of carbohydrate, $50 \mathrm{~g}$ of fat and $70 \mathrm{~g}$ of protein, with $67 \%$ of energy derived from carbohydrate [20].

\section{Breaking the chains}

In 1930, the physician William Collen sent Fred Banting a copy of his diabetes manual. 'The whole thing looks very complicated and difficult,' replied Banting, 'I would very much hate to be a diabetic and have to learn all about insulin and diets. I am perfectly certain that were I a diabetic patient, I would go to the doctor and tell him what I was going to eat and relieve myself of the worry by demanding of him a proper dose of insulin' [21]. The paediatrician Karl Stolte proposed his unmeasured ('free') diet in the following year, based on very much the same principle [22, 23]. Advocates of the free diet, as it evolved over the next 20 years, had some good arguments, and patients responded with enthusiasm, for their meals were now a joy to eat 'rather than a problem in arithmetic and a trial in self abnegation' [10]. Paediatricians were happy to release the children in their care from the psychological strait-jacket of the stricter regimen, and noted with some glee that Priscilla White reported severe stunting of growth in 5\% of her childhood patients at the Joslin Clinic [24], which they attributed to under-nutrition. Adults, meanwhile, reported improved energy and well-being, and the better nourishment provided by a free diet was considered to improve resistance to acute bacterial infection or tuberculosis, dreaded complications in the pre-antibiotic era. Last but not least, free diets reduced the risk of disabling hypoglycaemia [25].

\section{War and peace}

The early euphoria that surrounded insulin therapy shaded into a slow realisation that those who survived a metabolic death from diabetes were dying from vascular disease, and the issue of free diet became subsumed in the wider debate about control and complications. Traditionalists such as Joslin maintained - with some fervour-that glucose control was the prerequisite to extended life, while opponents such as Edward Tolstoi pointed out that Joslin's published data made it abundantly clear that his own patients were dying in droves from vascular complications [26]. Tolstoi considered glucose to be a harmless waste product, unrelated to vascular disease. This being the case, one daily injection of protamine zinc insulin would ensure that sufficient carbohydrate was assimilated to inhibit protein breakdown, beyond which point the body could be relied on to discard any unwanted glucose in the urine. Otherwise said, if complications are unavoidable, eat, drink and be merry, for tomorrow you die. Common sense has often shielded patients from the therapeutic enthusiasm of their physicians, and one visiting British physician learned from Tolstoi's dietitian that his female patients had discovered that pruritus vulvae, a common blight of the free diet, could be avoided by restricting their carbohydrate intake [27].

\section{Low carbohydrate...}

In 1958 William Daughaday commented on behalf of the American Dietetic Association that 'uncertainty exists in the minds of many physicians today concerning the therapeutic role of diet in diabetes'. He could find only three arguments 
to support its role: first, that it is a valuable educational procedure leading to optimal nutrition; second, that it can avoid the need for insulin; and third, that properly spaced food intake can reduce the risk of hypoglycaemia. Glucose control and prevention of vascular disease are notably absent from this list of benefits. He proposed that carbohydrate should provide no more than $40 \%$ of total calories, avoided discussion of free diet, and dismissed the high carbohydrate regimen with the comment that carbohydrate restriction is an essential feature of the diabetic diet [28].

\section{High carbohydrate...}

Kelly West, among others, rediscovered the high carbohydrate diet in the 1960s. He was astonished to discover when writing up his results that 'very similar experiments had been done by Himsworth, with the same results. Over and over again this phenomenon has been rediscovered - and subsequently forgotten or disregarded' [29]. Even those who remained unconvinced as to the virtue of a high carbohydrate diet were persuaded of the need to reduce fat, and the new diet was greeted with particular enthusiasm by those who had rediscovered that a high fat intake might be bad for the heart. Concerns about 'diet heart' powered many investigations into the virtues of polyunsaturated fats and fish oils [30], and the new high carbohydrate/low fat recommendations were formally recognised by the ADA in 1971 [31].

\section{Normal eating...}

Michael Berger and colleagues reintroduced a more liberal diet in 1983 as one element of an intensified training programme designed to empower the patient on insulin [32]. This, unlike the original free diet, was not in any way associated with a relaxed approach to glucose control, for the aim was to demonstrate that a less restricted way of life is compatible with good control. This regimen reached the UK in a form known as DAFNE (dietary adjustment for normal eating), and has been marketed with some skill, for it is only available through a limited number of registered centres, manned by specially trained health professionals (failure is otherwise guaranteed) and has thus gained a certain mystique more usually associated with expensive proprietary diets. It relies upon active and informed participation by the user and, possibly for this reason, works reasonably well [33].

\section{And the pre-insulin diet...}

Thomas Atkins reinvented the nineteenth century Banting diet in 1963, although it took another 30 years to reach prime time in the public consciousness. His regimen closely resembled the 'Eskimo diet' that Joslin had inflicted upon his mother in 1898 [4], the actual Inuit diet advocated for health reasons by the explorer Vilhjalmur Stefansson [34], and the diet tested upon overweight DuPont executives by Alfred Pennington in the 1930s. It should by now come as no surprise to the reader that the new diet worked (for some), generated passion, was condemned, vindicated, grudgingly accepted and finally forgotten.

\section{The rich man's tapeworm}

What is eaten is one thing, what is absorbed is another. Complex carbohydrates enter the circulation slowly, thus reducing post-meal glucose excursions. The high fibre diet has long been popular with the British, who traditionally consider the large intestine an unhygienic organ with undesirable contents. Unprocessed food forces this indolent stretch of bowel to exercise, and Dr Allinson's whole wheat/wholegrain flour, introduced for this purpose in 1892, has held its own in the market ever since. White flour, in contrast, was seen as an open invitation to intestinal laziness, toxic putrefaction and cancer of the bowel: a vigorous publicity campaign was waged against it in the 1920s [35, 36]. Later writers revived this school of thought with the claim that a high fibre diet will prevent diverticular disease, bowel cancer, varicose veins and haemorrhoids [37], whilst improving postprandial glucose control in diabetes. The glycaemic index, first devised in 1980 [38], made no such claims, but became popular for glucose control. Pharmacological alternatives to dietary abstinence - 'the rich man's tapeworm'-appeared, and enzyme inhibitors were used to block the intestinal absorption of disaccharides or fat, while the rate of glucose entry into the circulation has been modulated by inhibition of gastric emptying, one of the less heavily emphasised benefits of agents such as exenatide.

\section{Control and complications}

Diet has always generated passion, and passion in science is an infallible marker of lack of evidence. Then, as now, some physicians based their whole approach to the treatment of diabetes upon diet, while others virtually ignored it. The sad irony of the heated and long-running debate about control and complications is that glycated haemoglobin measurement would subsequently reveal that overall glucose control differed much less between regimens than the proponents of tight control would have been willing to believe. They lacked the technology to do better. Despite so much uncertainty, experience suggested that the laissez-faire 
approach was harmful [39], and the balance of opinion reached its tipping point with a celebrated debate in the New England Journal of Medicine in 1976 [40]. The 60-year-old argument was not finally resolved until the results of the Diabetes Control and Complications Trial were published in 1993 [41] and confirmed the influence of glucose control upon microvascular complications beyond dispute; its relation to arterial disease still gives rise to some controversy.

\section{Plus ça change...}

'The thing that hath been, it is that which shall be; and that which is done is that which shall be done: and there is no new thing under the sun' [42]. Affluent humans eat more than they need, gain weight and try to shed it, develop diabetes and try to control it. There will always be those to tell them that they can lose weight without eating less, in defiance of the laws of thermodynamics, and that one particular diet is better for diabetes than all the rest. Since the familiar diets will already have been tried, these already carry the stigmata of failure. Novelty is thus the essence of dietary advice and, given that there are relatively few possible permutations of carbohydrate, fat and protein, such advice will no doubt continue to be recycled ad infinitum.

Admittedly, some advice is needed. In 2008 the ADA followed national guidelines for the non-diabetic population in advising a minimum carbohydrate intake of $130 \mathrm{~g}$ daily, with $45-65 \%$ of energy needs obtained from carbohydrate, whilst conceding that a lower carbohydrate diet might also be OK [3]. The brief précis of this lengthy and learned document is that the person with diabetes should eat what the rest of us are supposed to be eating, and that the evidence base for most recommendations is modest at best. As the Swedish paediatrician Lichtenstein commented 65 years earlier, 'If any valid scientific grounds for the superiority of a certain form of diet had existed, this diet would doubtless have soon superseded all the others. No such development has taken place' [25].

Ask the wrong question and you will reach the wrong conclusion. Dietary compliance is hard to measure, but it is notorious that many patients know little about their prescribed diet and have difficulty in following it [43]. Systematic reviews suggest that its benefits are modest at best [44], and the fact that no one diet has outperformed the rest in terms of glucose control (we are not here considering weight) has encouraged those who are so inclined to dismiss diet altogether. This wrong conclusion having been drawn, we now live in the worst of all possible worlds. Leading specialists dismiss diet with attempted humour ('OK for Alcatraz', as one such wit expressed it), and put all their trust in pills. 'Patients can't stick to a diet', they will tell you, apparently unaware of the overwhelming evidence that people don't take their pills either [45]. Professional sensitivities add to the confusion, for the diabetes physician, who once knew all there was to be known about diet, is now supremely ignorant about the whole subject. 'Whereof one cannot speak, thereof one must be silent,' said the philosopher Wittgenstein [46], but physicians have never taken this advice seriously, and have damned diet with faint praise. This half-hearted approach is exemplified in the recent ADA/European Association for the Study of Diabetes guidelines, which pay lip service to lifestyle change before advising us to start metformin from day one [47]. Life under communism was once summed up in the wry comment that 'we pretend to work, and they pretend to pay us'. Our patients might equally complain that we pretend to offer a diet, and they pretend to follow it.

Despair would be premature, for another conclusion has been staring us in the face all along. History teaches that our metabolic pathways are remarkably adept at converting whatever we eat into whatever we need, and can therefore function effectively across a wide range of dietary intake. Sadly for us, our metabolism is less versatile when it comes to chronic over-nutrition, and we are all over-nourished. No surprise, therefore, that calorie restriction works well for diabetes in most situations, and that both its incidence [48] and mortality [49] were dramatically reduced by enforced diet in wartime. The UK Prospective Diabetes Study (UKPDS) showed that energy restriction and weight loss can achieve glucose control, but this requires considerable commitment. An average loss of $16 \%$ ideal body weight was, for example, required to achieve the target value of $6 \mathrm{mmol} / 1$ in those with an initial fasting plasma glucose between 6 and $8 \mathrm{mmol} / \mathrm{l}$, while $41 \%$ loss was needed if the initial fasting value was between 12 and $14 \mathrm{mmol} / \mathrm{l}$. The trial thus confirmed that only a minority can achieve adequate glucose control by diet alone, and then only by a remarkable degree of dietary privation [50].

Does this mean, as some authorities suggest, that diet doesn't work? Of course not. Some diet is much better than no diet, and you can easily turn the argument on its head by pointing out that an individual who eats ad libitum will never achieve good glucose control, however much pharmacotherapy you fling in his direction. Show us a person with well-controlled diabetes, and we will show you someone who pays attention to what they eat, and who tends to eat sparingly. Diet enthusiasts will argue that people like this are in good control because they follow a diet, but the real answer is that they follow a diet because that is one of those things that people in good control do. People with wellcontrolled diabetes do everything well, which is why, to paraphrase Tolstoy (the novelist, not the physician), all wellcontrolled patients are alike, whereas each poorly controlled patient is poorly controlled in his or her own unique way. 
To end where we began: which diet is best for diabetes? One that is spare, sensible and taken with exercise; a diet for which pharmacotherapy is an adjunct, rather than a substitute. A diet that the patient believes in. Since dietary advice will be recycled for as long as humans eat more than they need, there will always be plenty to choose from. For diet is hope's sister, and we should never say goodbye to either, just au revoir.

Acknowledgement We thank R. Tattersall for his generosity in allowing us to draw upon unpublished material from a chapter he is writing on this topic.

\section{References}

1. Santayana G (1905) The life of reason, or the phases of human progress. Constable and Co, London

2. Woodyatt RT (1934) Round table conference on diabetes mellitus. Dietary trends. Bull NY Acad Med 10:335-346

3. American Diabetes Association (2008) Nutrition recommendations and interventions for diabetes. Diabetes Care 31(Suppl 1): S61-S78

4. Joslin EP (1917) Treatment of diabetes mellitus, 2nd edn. Lea and Febiger, Philadelphia

5. Malins J (1968) Clinical diabetes mellitus. Eyre and Spottiswood, London

6. Banting W (1864) Letter on corpulence, addressed to the public, 3rd edn. Harrison, London

7. Sandmeyer W (1895) Ueber die Folgen der partiellen Pancreasexstirpation beim Hund. Ztschr f Biol 31:12-85

8. Allan F (1913) Studies concerning glycosuria and diabetes. Leonard, Boston

9. Imamura T, Koffler M, Helderman JH et al (1988) Severe diabetes induced in subtotally depancreatized dogs by sustained hyperglycemia. Diabetes 37:600-609

10. Dunlop D (1966) Opening address. In: Duncan LJP (ed) Diabetes mellitus. University Press, Edinburgh

11. Bliss M (1983) The discovery of insulin. Harris, Edinburgh

12. Tattersall RB (1995) A force of magical activity: the introduction of insulin treatment in Britain 1922-1926. Diabet Med 12:739-755

13. Westman EC, Yancy WS, Humphreys M (2006) Dietary treatment of diabetes mellitus in the pre-insulin era (1914-1922). Perspect Biol Med 49:77-83

14. Chittenden RH (1907) Physiological economy in nutrition: with special reference to the minimal proteid requirement of the healthy man, an experimental study. Stokes, New York

15. West KM (1978) Epidemiology of diabetes and its vascular lesions. Elsevier, New York

16. Yang EJ, Kerver JM, Park YK, Kayitsinga J, Allison DB, Song WO (2003) Carbohydrate intake and biomarkers of glycemic control among US adults: the third National Health and Nutrition Examination Survey (NHANES III). Am J Clin Nutr 77:1426-33

17. Himsworth H (1934) High carbohydrate diets and insulin efficiency. BMJ ii:57-60

18. Adlersberg D, Porges O (1926) Zur Theorie und Praxis der kurativen Diabetesbehandlung. Klin Wschr 5:1451-1455 (in German)

19. Tompkins WA (1977) Continuing quest. Dr William Sansum's crusade against diabetes. Sansum Medical Research Foundation, Santa Barbara
20. Duncan GG (1951) Diabetes mellitus. Principles and treatment. Saunders, Philadelphia

21. Collen WS (1954) Regulated versus free diet in the treatment of diabetes mellitus. J Clin Nutr 2:195-203

22. Stolte K (1931) Freie Diät beim Diabetes. Med Klin 27:831-838 (in German)

23. Berger M (1999) Bedarfsgerechte insulintherapie bei freier kost, der beitrager von karl stolte nur klinischen diabetologie. Verlag Kirchheim, Mainz (in German)

24. White P (1937) Diabetes in childhood. In: Joslin EP (ed) The treatment of diabetes mellitus. 6th edn. Lea and Febiger, Philadelphia

25. Lichtenstein A (1943) Treatment of children's diabetes. Ten years' experience without dietetic restrictions. Acta Paediatr 32:556-576

26. Tolstoi E (1950) The free diet for diabetic patients. Am J Nursing 50:652-654

27. Walker JB (1964) Carbohydrate consumption and diabetes. Proc Nutr Soc 23:143-149

28. Daughaday WH (1958) Dietary treatment of adults with diabetes mellitus. J Am Med Assoc 167:859-862

29. West KM (1973) Diet therapy of diabetes: an analysis of failure. Ann Int Med 79:425-434

30. Le Fanu J (1999) The rise and fall of modern medicine. Little, Brown, London

31. Bierman EL, Albrink MY, Arky RA (1971) Special report: principles of nutrition and dietary recommendations for patients with diabetes mellitus. Diabetes 20:633-634

32. Muhlhauser I, Jörgens V, Berger $M$ et al (1983) Bicentric evaluation of a teaching and treatment programme for type 1 (insulin-dependent) patients: improvement of metabolic control and other measures of diabetes care for up to 22 months. Diabetologia 25:470-476

33. DAFNE Study Group (2002) Training in flexible, intensive insulin management to enable dietary freedom in people with type 1 diabetes: dose adjustment for normal eating (DAFNE) randomised controlled trial. BMJ 325:746-782

34. Lieb CW (1926) The effects of an exclusive, long-continued meat diet. Based on the history, experiences and clinical survey of Vilhjalmur Stefansson, Arctic explorer. JAMA 87:25-26

35. Lane WA (1927) Secrets of good health. Heinemann, London

36. Fishbein M (1932) Fads and quackery in healing. An analysis of the foibles of the healing cults, with essays on other peculiar notions in the health field. Blue Ribbon Books, New York

37. Trowell H (1976) Definition of dietary fiber and hypotheses that it is a protective factor in certain diseases. Am J Clin Nutr 29:417-427

38. Jenkins DJA, Wolever TMS, Taylor RH et al (1981) Glycemic index of foods: a physiological basis for carbohydrate exchange. Am J Clin Nutr 34:362-366

39. Dunlop DM (1954) Are diabetic degenerative complications preventable? BMJ 2:383-385

40. Cahill GF, Etzwiler DD, Freinkel N (1976) "Control" and diabetes. N Engl J Med 294:1004

41. The Diabetes Control and Complications Trial Research Group (1993) The effect of intensive treatment of diabetes on the development and progression of long-term complications in insulin-dependent diabetes. N Engl J Med 329:977-986

42. Ecclesiastes 1:9

43. van der Laar FA, Akkermans RP, van Binsbergen JJ (2007) Limited evidence for effects of diet for type 2 diabetes from systematic reviews. Eur J Clin Nutr 61:929-937

44. Stone DB (1961) A study of the incidence and causes of poor control in patients with diabetes mellitus. Am J Med Sci 241:436-442

45. Cramer JA (2004) A systematic review of adherence with medications for diabetes. Diabetes Care 27:1218-1224 
46. Wittgenstein L (1922) Tractatus Logico-Philosophicus, translated by Ogden CK. Routledge and Kegan Paul, London

47. Nathan DM, Buse JB, Davidson MB et al (2006) Management of hyperglycaemia in type 2 diabetes: a consensus algorithm for the initiation and adjustment of therapy. A consensus statement from the American Diabetes Association and the European Association for the Study of Diabetes. Diabetologia 49:1711-1721
48. Westlund K (1966) Incidence of diabetes mellitus in Oslo, Norway, 1925 to 1954. Br J Prev Soc Med 20:105-116

49. Trowell H (1974) Diabetes death rates in England and Wales 1920-70 and food supplies. Lancet 2:998-1002

50. UKPDS Group (1990) UK Prospective Diabetes Study 7: response of fasting plasma glucose to diet therapy in newly presenting type II diabetic patients. Metabolism 39:905-912 